\title{
ASTER Global DEM Version 3, and new ASTER Water Body Dataset
}

\author{
M. Abrams a \\ a Jet Propulsion Laboratory, California Institute of Technology, Pasadena, USA - mjabrams@jpl.nasa.gov
}

KEY WORDS: DEM, ASTER, Water body mask

\begin{abstract}
:
In 2016, the US/Japan ASTER (Advanced Spaceborne Thermal Emission and Reflection Radiometer) project released Version 3 of the Global DEM (GDEM). This $30 \mathrm{~m}$ DEM covers the earth's surface from 82N to 82S, and improves on two earlier versions by correcting some artefacts and filling in areas of missing DEMs by the acquisition of additional data. The GDEM was produced by stereocorrelation of 2 million ASTER scenes and operation on a pixel-by-pixel basis: cloud screening; stacking data from overlapping scenes; removing outlier values, and averaging elevation values. As previously, the GDEM is packaged in 23,000 1x1 degree tiles. Each tile has a DEM file, and a NUM file reporting the number of scenes used for each pixel, and identifying the source for fill-in data (where persistent clouds prevented computation of an elevation value). An additional data set was concurrently produced and released: the ASTER Water Body Dataset (AWBD). This is a 30m raster product, which encodes every pixel as either lake, river, or ocean; thus providing a global inland and shore-line water body mask. Water was identified through spectral analysis algorithms and manual editing. This product was evaluated against the Shuttle Water Body Dataset (SWBD), and the Landsat-based Global Inland Water (GIW) product. The SWBD only covers the earth between about 60 degrees north and south, so it is not a global product. The GIW only delineates inland water bodies, and does not deal with ocean coastlines. All products are at 30m postings.
\end{abstract}




\section{INTRODUCTION}

\subsection{ASTER instrument}

The Advanced Spaceborne Thermal Emission and Reflection Radiometer (ASTER) is a 15-channel imaging instrument operating on NASA's Earth Observing Terra morning orbital platform since 1999. ASTER was built and provided by Japan's Ministry of Economy, Trade, and Industry (METI). ASTER has three separate optical subsystems: the visible and near-infrared (VNIR) radiometer, acquiring images in 3 bands with a $15 \mathrm{~m}$ instantaneous field of view (IFOV), and an additional backward-looking band for stereo; the shortwave infrared (SWIR) radiometer, acquiring images in 6 bands with a $30 \mathrm{~m}$ IFOV; and the thermal infrared (TIR) radiometer, acquiring images in 5 bands with a $90 \mathrm{~m}$ IFOV. ASTER acquires images in all bands with a swath width of $60 \mathrm{~km}$. It orbits the earth in a sun-synchronous near-polar orbit, with an equator crossing time of 10:30am, and the daytime repeat visit interval is 16 days at the equator.

\subsection{ASTER Global Digital Elevation Model (GDEM)}

On June 29, 2009 the Ministry of Economy, Trade, and Industry (METI) of Japan and the U.S. National Aeronautics and Space Administration (NASA), jointly released Version 1 of the global digital elevation model (GDEM) of the Earth's land surface, derived from 1.7 million images acquired by ASTER (Abrams et al., 2010). The ASTER GDEM is the most up-to-date, high spatial resolution, complete digital topographic data set of the Earth available at no cost to the public, covering the global land surface from 83 degrees north to 83 degrees south latitude. An updated Version 2 was released in October, 2011. Additional scenes were added to fill in missing data; many of the artefacts were eliminated, particularly those due to remnant cloud edges.

Prior to the release of the ASTER GDEM, the most complete DEM available to the public was the Shuttle Radar Topography Mission (SRTM) data set (Farr and Kobrick, 2000; Farr et al., 2007). SRTM was a joint mission of NASA, German Aerospace Center, and the National Geospatial-Intelligence Agency. The SRTM data were created using interferometric processing of Lband synthetic aperture radar (SAR) data. The SRTM DEM is a surface model, with canopy, as is the ASTER GDEM. The SRTM data were released to the public at $90 \mathrm{~m}$ postings for areas outside the U.S. (versus $30 \mathrm{~m}$ for GDEM), and $30 \mathrm{~m}$ postings for the US and its Territories. The SRTM DEM covers the Earth from 60 degrees north to 57 degrees south latitude, thus missing the land masses north of 60 degrees (Greenland; northern Canada, Europe, Asia, and Alaska) and Antarctica (that are covered by GDEM).

GDEM was produced from the entire 1.7 million scene ASTER archive. In addition to VNIR band 3 acquiring a nadir-look, there is a backward-looking telescope operating in the same spectral range. Every time there is a VNIR data acquisition, a stereo pair is collected. The backward-looking and nadir visible bands have a 28 degree look angle, thus giving a base-to-height ratio of 0.6. The pixel size of the visible and near infrared bands (and the stereo band) is $15 \mathrm{~m}$. Standard stereocorrelation was used to produce individual scene models at $30 \mathrm{~m}$ postings. Cloud screening and quality control were applied before stacking and averaging elevations on a per pixel basis (Fujisada et al., 2012). The resulting data were partitioned into 22,600 $1 \mathrm{x}$ 1 degree tiles.

\subsection{GDEM Version 3 and ASTER Water Body Data Set}

In 2016, the ASTER team released GDEM Version 3. In addition to Digital Elevation Models for each tile, a separate data set was included that identified water bodies. An auxiliary data plane identified the water bodies as either river, lake, or ocean. The AWBD was used as a mask while creating the DEM, so shorelines and lake boundaries are integrated. In addition, rivers have descending elevations from their headwaters to their junction with other rivers, or junction with the ocean. Fujisada (2012) describes in detail the methodology used to identify water, how it was assigned to three categories, and elevation values determined.

\section{COMPARISON OF WATER BODY DATA SETS}

\subsection{Shuttle, and Landsat Water Body Data}

There are two other water body data sets that the AWBD was compared with. The SRTM (Shuttle Radar Topography Mission) Water Body Data (SWBD) is a geographical dataset encoding high-resolution worldwide coastline outlines in vector format, published by NASA and designed for use in GIS and mapping applications (USGS, 2016). It was created for the US National Geospatial-Intelligence Agency as a complementary product during editing of the DEM data base of the SRTM. SWBD covers the Earth's surface between 56 degrees south and 60 degrees north latitudes. It is distributed in ESRI shapefile vector format, divided into $12,000+$ files, each covering one 1 by 1 degree tile.

The Landsat Global Inland Water (GIW) product was released in 2015 (Feng et al., 2015) as part of a NASA funded effort. The dataset is primarily derived from the Global Land Survey data collection, a mosaic of Landsat data for the year around 2000. The GIW is a global, 30-m-resolution inland surface water dataset, produced with an automated algorithm using Landsat-based surface reflectance estimates, multispectral water and vegetation indices, terrain metrics, and prior coarseresolution water masks.

\subsection{Data set comparisons}

A test area in northern Minnesota, USA was examined from the AWBD and the GIW. This area has hundreds of small lakes and provides a good test of the detection capability of both data sets (Figure 1). Lakes identified in both data sets are depicted in magenta; lakes found only in the GIW data set are in yellow and blue. Almost all of the lakes were found in both data sets. A few are only in the GIW. Overall, the two data sets are quite comparable. 


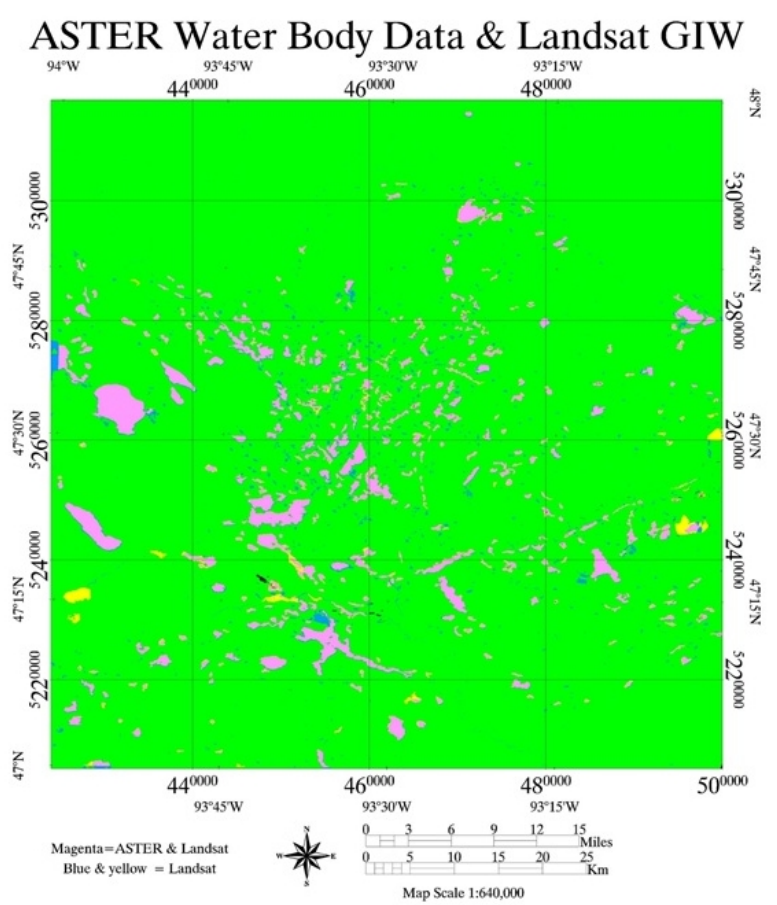

Figure 1. Lakes defined in AWBD and GIW. AWBD and GIW overlap lakes are in magenta; GIW only lakes are in yellow and blue. Area is in northern Minnesota, USA.

A tile located at N38W77 was examined from the AWBD and SWBD sets. The area covers part of the Chesapeake Bay in the eastern USA, and has also ocean coastline (Figure 2).

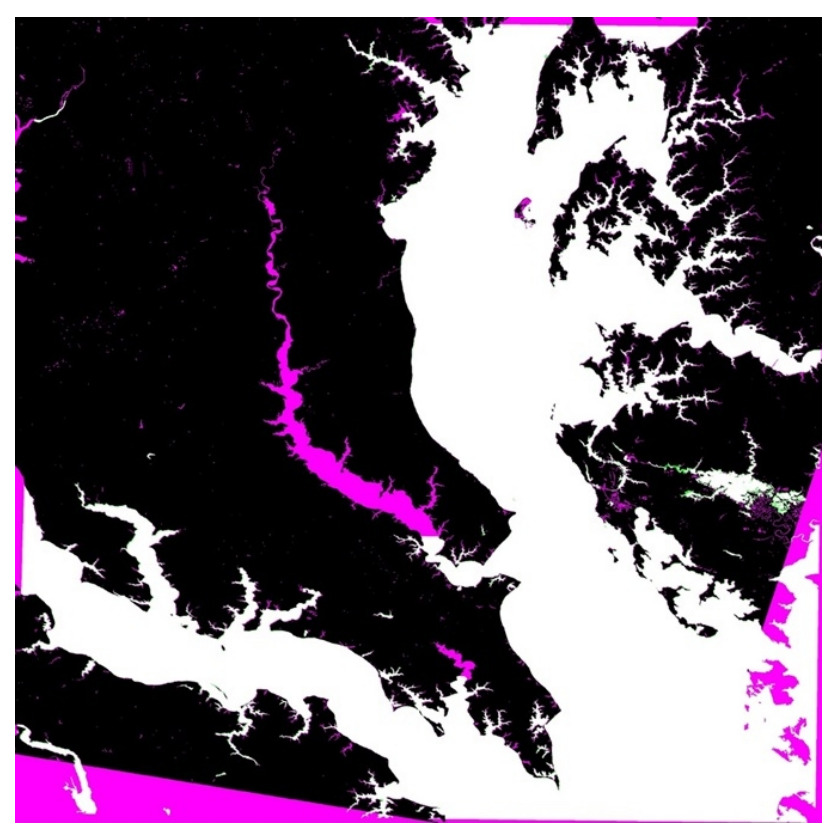

Figure 2. Chesapeake Bay, eastern USA. Comparison of SWBD and AWBD. Coincident water bodies are in white; ASTER only water bodies are in green; SWBD only water bodies are in magenta.

The majority of the bay waters and tributary rivers and estuaries are coincidentally identified on both data sets. Note one large tributary that is not found in the AWBD data set. A few small tributaries are missed on the SWBD.
A tile in Chile's Patagonia region illustrates the major shortcoming of the GIW, compared to the AWBD (Figure 3).

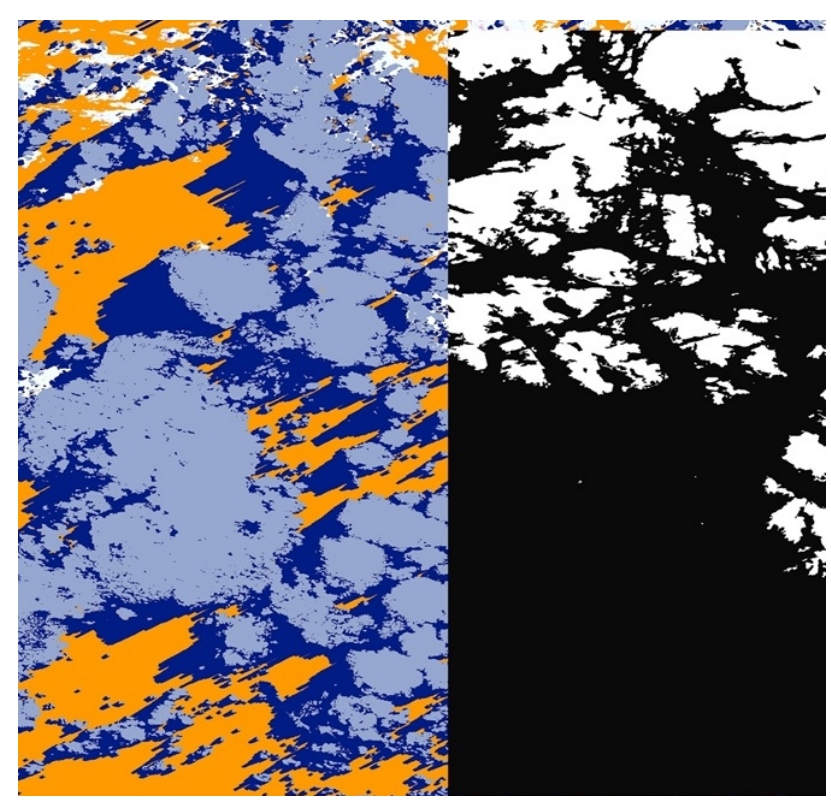

Figure 3. Patagonia tile divided in half: GIW (left) and AWBD (right). See text for explanation.

The left half of the image shows the GIW, with land in white, water in orange, and clouds in gray. The right half of the image shows the AWBD, with land in white, and water in black. Obviously, the GIW, because it is only for inland water, does not properly deal with the coastline, and particularly with islands. In addition, because the original data set is for only a few years around 2000, the presence of perennial clouds contaminates the data. AWBD is based on 13 years of data, so a cloud-free mosaic can be made from which to extract the landwater boundary.

\section{CONCLUSIONS}

The AWBD is unique in that it has excellent water body data for the entire globe from 83 degrees north to 83 degrees south. The SWBD is of equal quality (with some glaring errors (not shown here), but only covers the Earth from 60 degrees north to 57 degrees south. It is also available only in vector format. The Landsat GIW suffers from the time-restricted data base used, so clouds are a serious problem. The ocean coastline was not extracted from the original data set. On the other hand, its identification and delineation of inland water bodies is at least as good as AWBD, and better in places. An obvious project suggests itself: to merge the best, most accurate information from all three data sets, and create a single, global water body data set.

\section{ACKNOWLEDGEMENT}

Work by Abrams was performed at the Jet Propulsion Laboratory/California Institute of Technology under contract with the National Aeronautics and Space Administration.

\section{REFERENCES}

Abrams, M., Tsu, H., Hulley, G., et al., 2015. The Advanced Spaceborne Thermal Emission and Reflection Radiometer 
(ASTER) after fifteen years: Review of global products. International Journal of Applied Earth Observation and Geoinformation, 38, pp. 292-301.

Farr, T., M. Kobrick, 2000, Shuttle Radar Topography Mission produces a wealth of data, Amer. Geophys. Union Eos, 81, 583585.

Farr, T., et al. 2007, The Shuttle Radar Topography Mission, Rev. Geophys., 45, RG2004, doi:10.1029/2005RG000183.

Feng, M., Sexton, J., Channan, S., Townshend, J., 2015. A global, high-resolution $(30 \mathrm{~m})$ inland water body dataset for 2000: first results of a topographic-spectral classification. Intl. J. Digital Earth. 6(5). Pp. 1-21.

Fujisada, H., Urai, M., Iwasaki, A., 2012. Technical Methodology for ASTER Global DEM. IEEE Trans. Geosci. Rem. Sens. 50(10), pp. 3725-3736.

USGS, 2016, SRTM Water Body Dataset. https://lta.cr.usgs.gov/srtm_water_body_dataset, accessed February 24, 2016. 